\title{
Accelerating Compression Time of the Standard JPEG by Employing the Quantized YCbCr Color Space Algorithm
}

\author{
Trini Saptariani, Sarifudin Madenda, Ernastuti, Widya Silfianti \\ Department of Computer Science, Gunadarma University, Indonesia
}

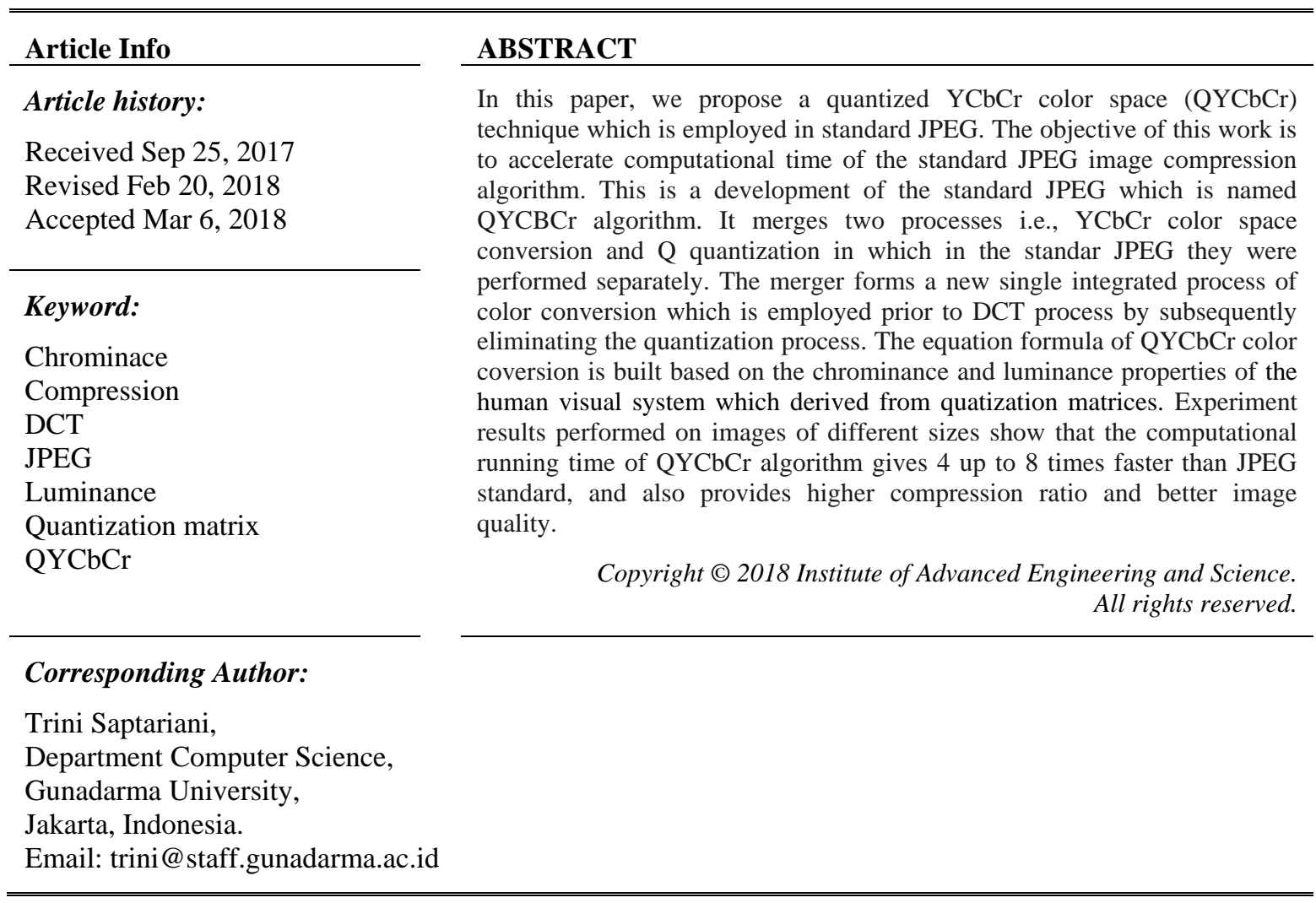

\section{INTRODUCTION}

The development of image acquisition technology today continues to grow very rapidly resulting in excellent image quality. This gives a positive impact on users who need a good image quality, as well as a positive impact on the development of information technology and types of technologies such as biomedical, astronomical, remote sensing, and archaeological fields that mostly use the image as data to be studied. Image quality can be improved also followed by the large volume of data generated so that impacting the need for increased memory capacity. It also has an impact on the transmission speed at the time of image data exchange through a communication network. These impacts can be anticipated through the application of image compression algorithms in image acquisition technology devices such as cameras and videos. The image compression algorithm commonly used in this technology for image file storage is JPEG. JPEG is an algorithm type of Lossy compression (compression accompanied by the change in data), which is a compression technique by minimizing the number of bits (reducing value) through quantization process accompanied by rounding the result value [1]. Quality of compression can be maintain with the quantization process is carried out in a frequency domain such as DCT (Discreet Cosine Transform) which is applied in JPEG algorithm [2]-[4].

The two main processes in JPEG image compression are the DCT and quantization processes, where these two processes are performed separately and greatly determine the magnitude of ratio and quality of the compression image. Figure 1 shows the general scheme of a standard JPEG image compression model consisting of two parts: image compression in the top section and decompression in the bottom section [1]. 


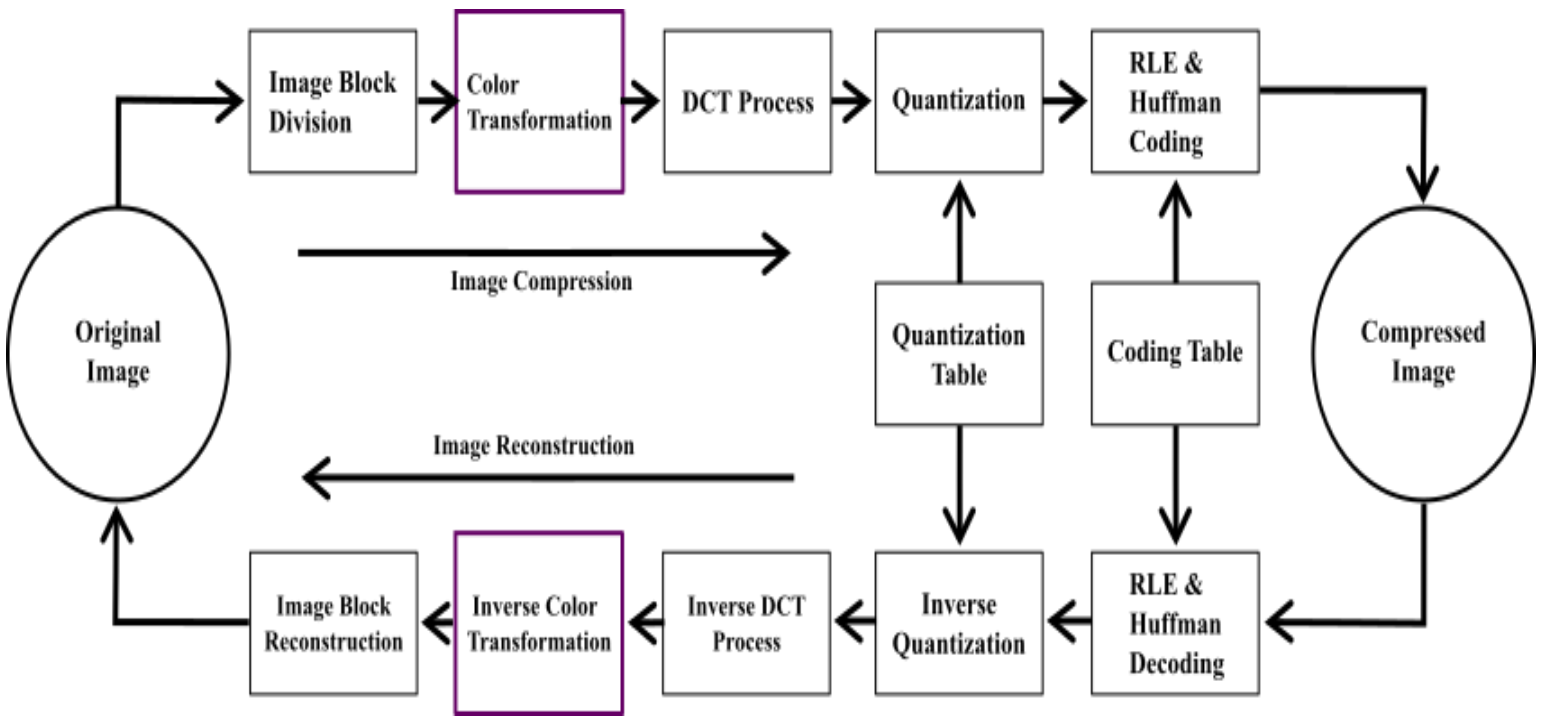

Figure 1. Standard JPEG image compression and decompression scheme

\section{DCT AND QUANTIZATION PROCESSES ON STANDARD JPEG}

This section deals specifically with the DCT and quantization processes that are directly related to the research proposals in this paper. Equation 1 denotes the DCT process, which converts image data from the spatial domain to the frequency domain, where [f] is the input of an image block of $8 \mathrm{x} 8$ pixels, [DCT] is the DCT matrix, $[\mathrm{DCT}]^{\mathrm{T}}$ is the transpose matrix of [DCT], and $[\mathrm{F}]$ is the result of the DCT process [5].

$$
[F]=([D C T] \cdot[f]) \cdot[D C T]^{T}
$$

with:

$$
\begin{gathered}
{[D C T]=\left(\begin{array}{ccccccccc}
0.3536 & 0.3536 & 0.3536 & 0.3536 & 0.3536 & 0.3536 & 0.3536 & 0.3536 \\
0.4904 & 0.4157 & 0.2778 & 0.0975 & -0.0975 & -0.2778 & -0.4157 & -0.4904 \\
0.4619 & 0.1913 & -0.1913 & -0.4619 & -0.4619 & -0.1913 & 0.1913 & 0.4619 \\
0.4157 & -0.0975 & -0.4904 & -0.2778 & 0.2778 & 0.4904 & 0.0975 & -0.4157 \\
0.3536 & -0.3536 & -0.3536 & 0.3536 & 0.3536 & -0.3536 & -0.3536 & 0.3536 \\
0.2778 & -0.4904 & 0.0975 & 0.4157 & -0.4157 & -0.0975 & 0.4904 & -0.2778 \\
0.1913 & -0.4619 & 0.4619 & -0.1913 & -0.1913 & 0.4619 & -0.4619 & 0.1913 \\
0.0975 & -0.2778 & 0.4157 & -0.4904 & 0.4904 & -0.4157 & 0.2778 & -0.0975
\end{array}\right)} \\
{[D C T]^{\gamma}=} \\
\left.\begin{array}{rrrrrrrrrr}
0.3536 & 0.4904 & 0.4619 & 0.4157 & 0.3536 & 0.2778 & 0.1913 & 0.0975 \\
0.3536 & 0.4157 & 0.1913 & -0.0975 & -0.3536 & -0.4904 & -0.4619 & -0.2778 \\
0.3536 & 0.2778 & -0.1913 & -0.4904 & -0.3536 & 0.0975 & 0.4619 & 0.4157 \\
0.3536 & 0.0975 & -0.4619 & -0.2778 & 0.3536 & 0.4157 & -0.1913 & -0.4904 \\
0.3536 & -0.0975 & -0.4619 & 0.2778 & 0.3536 & -0.4157 & -0.1913 & 0.4904 \\
0.3536 & -0.2778 & -0.1913 & 0.4904 & -0.3536 & -0.0975 & 0.4619 & -0.4157 \\
0.3536 & -0.4157 & 0.1913 & 0.0975 & -0.3536 & 0.4904 & -0.4619 & 0.2778 \\
0.3536 & -0.4904 & 0.4619 & -0.4157 & 0.3536 & -0.2778 & 0.1913 & -0.0975
\end{array}\right)
\end{gathered}
$$

Furthermore, the values in the matrix $[\mathrm{F}]$ are quantized as shown by equation (2). Quantization is the process of dividing each element of the matrix $\mathrm{F}(\mathrm{n}, \mathrm{m})$ against the element of the quantization matrix $\mathrm{Q}(\mathrm{n}, \mathrm{m})$ [6] [7]. Figure 2 shows an example of DCT process result and followed by quantization process. We can see the result of the quantization process, the values in this matrix become smaller and a lot of redundant values, especially the value of 0 . This allows the matrix values to be encoded with a smaller number of bits with the help of zig-zag coding and RLE-Huffman coding. 


$$
F^{Q}(n, m)=\operatorname{round}\left(\frac{F(n, m)}{Q(n, m)}\right)
$$

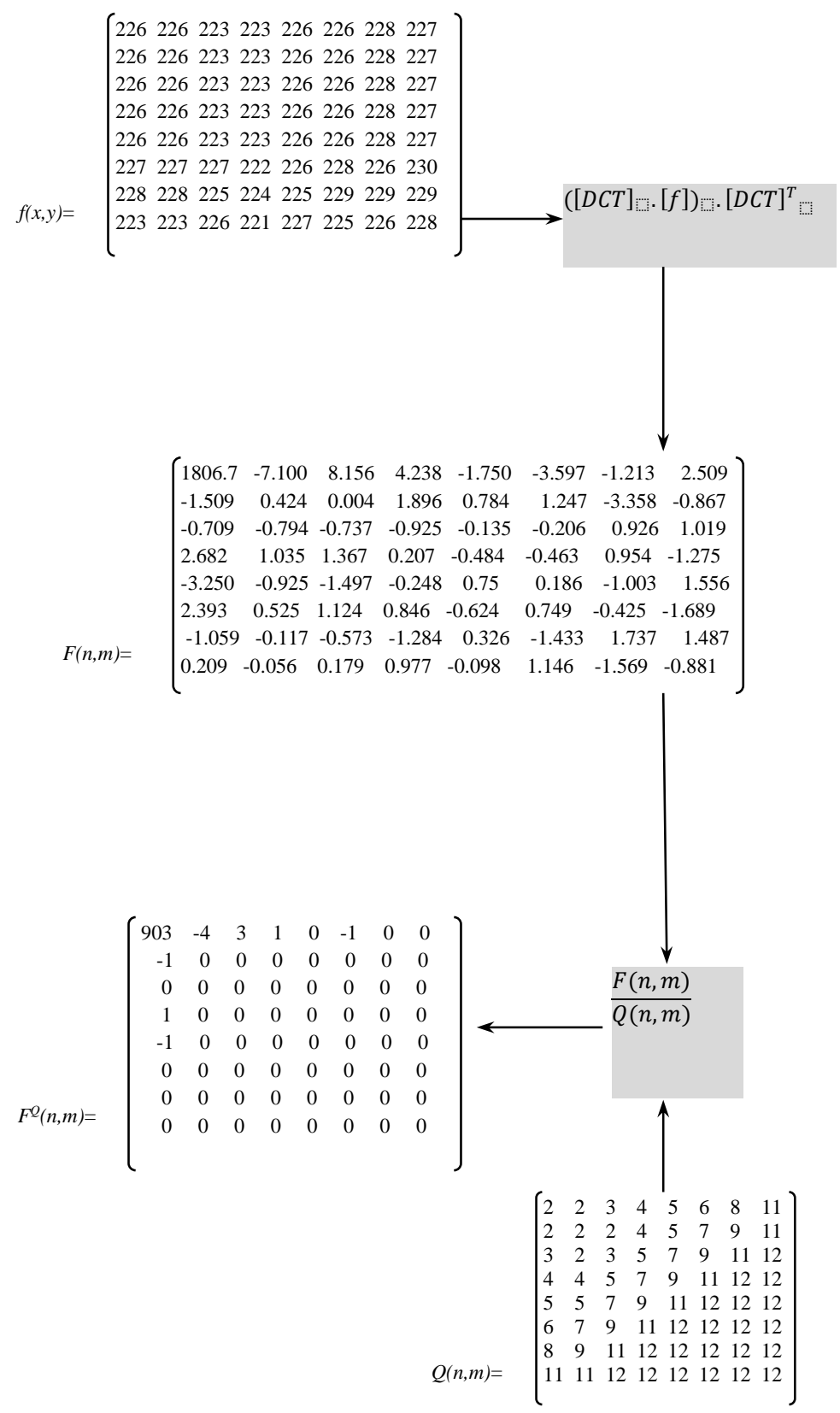

Figure 2. Example of DCT and quantization process

In the decompression process, to return the matrix $\mathrm{F}^{\mathrm{Q}}(n, m)$ to its initial data $f(n, m)$, then the inverse process must be done. This process is carried out by equations (3) and (4), which is preceded by the dequantization process and followed by the inverse DCT process. Here $[\mathrm{iDCT}]=[\mathrm{DCT}]^{\mathrm{T}}$ and $[\mathrm{iDCT}]^{\mathrm{T}}=[\mathrm{DCT}]$. Example invers process: iDCT and dequantization as shown in Figure 3.

$$
\begin{aligned}
& F(n, m)=F^{Q}(n, m) \cdot Q(n, m) \\
& {[f]=([i D C T] \cdot[F]) \cdot[i D C T]^{T}}
\end{aligned}
$$




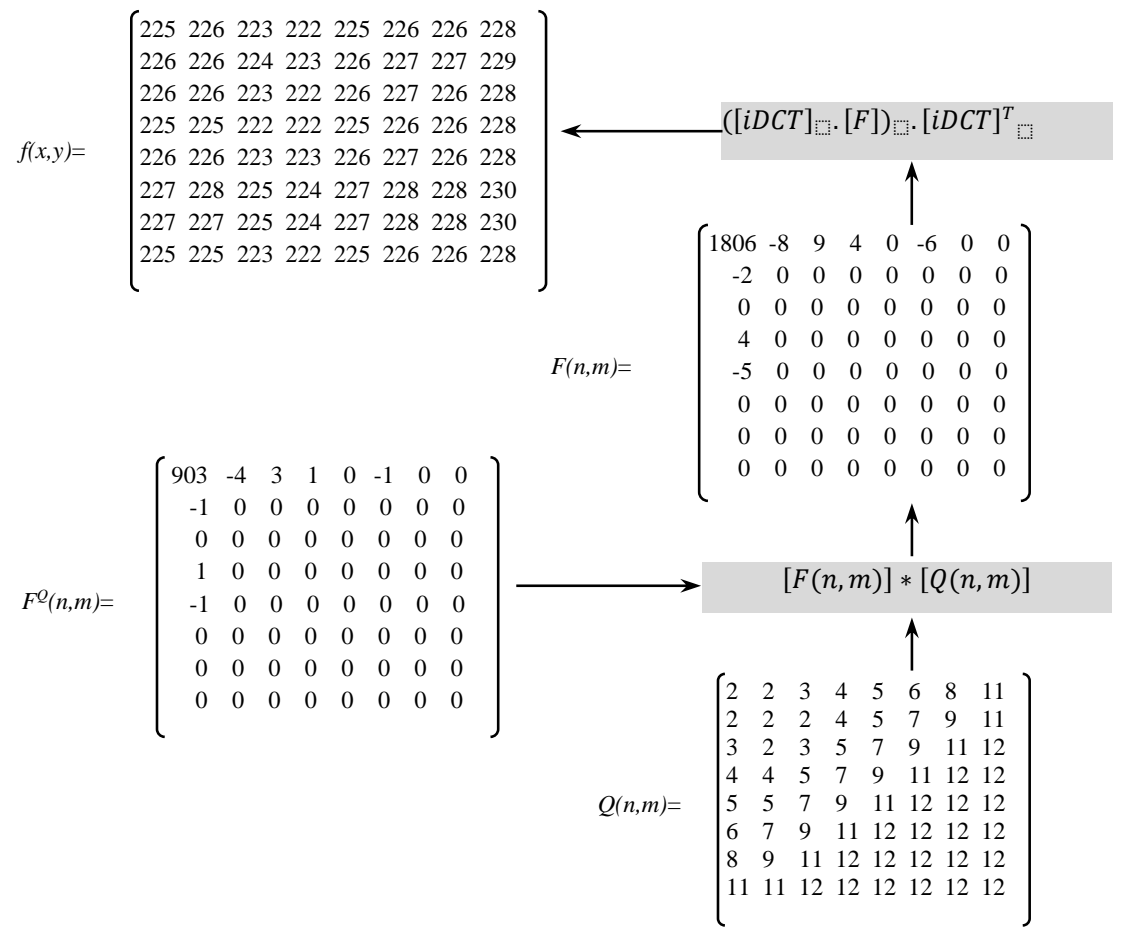

Figure 3. Example Invers Process: iDCT \& Dequantization

\section{PROPOSED METHOD}

In Equation 2, the quantization process of a matrix having $8 \times 8$ elements requires 64 divisions and the dequantization process in Equation 3 needs 64 multiplications. This means for the image size of NxM pixels, NxM division and NxM multiplication are required [6]. This process is quite time consuming, so we need to find solutions on how to accelerate the compression and decompression processes. The algorithm of combining DCT and quantization processes to accelerate the compression and decompression processes of JPEG image has been studied previously in [8]-[11]. In this section, we propose solutions by using the YCbCr-quantized color space conversion model. The basic idea of this method is to use Q matrix that has a homogeny value, so that one constant value can express $\mathrm{Q}$. Therefore, the quantization process can be carried out at the beginning along with the $\mathrm{YCbCr}$ color conversion process. [12]-[14]

In standard JPEG, the RGB to $\mathrm{YCbCr}$ color conversion is given by Equation 5 and from $\mathrm{YCbCr}$ to RGB given by Equation 6. Our proposed method is to integrate the Q quantization process into the $\mathrm{YCbCr}$ equation, so it is called YCbCr-quantized or QYCbCr. Equations 7 and 8 show the RGB to QYCbCr conversion process that we propose. The next question is what are the quantization values for the luminance component $\mathrm{Y}\left(\mathrm{Q}_{\mathrm{Y}}\right)$ and for the chrominance components $\mathrm{Cb}$ and $\mathrm{Cr}\left(\mathrm{Q}_{\mathrm{C}}\right)$ ?

$$
\begin{aligned}
& {\left[\begin{array}{c}
Y \\
C b \\
C r
\end{array}\right]=\left[\begin{array}{ccc}
0.299 & 0.587 & 0.114 \\
0.500 & -0.419 & 0.081 \\
-1.169 & -0.331 & 0.500
\end{array}\right]\left[\begin{array}{l}
R \\
G \\
B
\end{array}\right]} \\
& {\left[\begin{array}{l}
R \\
G \\
B
\end{array}\right]=\left[\begin{array}{ccc}
1 & 0.0 & 1.402 \\
1 & 1.772 & 0.0 \\
1 & -0.344 & -0.741
\end{array}\right]\left[\begin{array}{c}
Y \\
C b \\
C r
\end{array}\right]} \\
& {\left[\begin{array}{c}
Y \\
C b \\
C r
\end{array}\right]=\left[\begin{array}{ccc}
(0.299 & 0.587 & 0.114) / Q_{Y} \\
(0.500 & -0.419 & 0.081) / Q_{C} \\
(-1.169 & -0.331 & 0.500) / Q_{C}
\end{array}\right]\left[\begin{array}{l}
R \\
G \\
B
\end{array}\right]}
\end{aligned}
$$




$$
\left[\begin{array}{l}
R \\
G \\
B
\end{array}\right]=\left[\begin{array}{ccc}
(0.299 & 0.587 & 0.114) / Q_{Y} \\
(0.500 & -0.419 & 0.081) / Q_{C} \\
(-1.169 & -0.331 & 0.500) / Q_{C}
\end{array}\right]^{-1}\left[\begin{array}{c}
Y \\
C b \\
C r
\end{array}\right]
$$

The JPEG standard compression always uses a chrominance quantization value greater than a luminance quantization value. This corresponds to the human visual system that is more sensitive to luminance change than small change of color or chrominance. Example, Photoshop software uses a different quantization matrix $\mathrm{Q}$ for photography and for web applications. For photography application, Photoshop CS uses 12 quantization matrices of $\mathrm{Q}_{12}, \mathrm{Q}_{11}, \ldots, \mathrm{Q}_{1}$ resulting different compression ratio and image quality. Below are two examples of quantization matrices $\mathrm{Q}_{12}$ and $\mathrm{Q}_{9}$, where $\mathrm{Q}_{i L}$ and $\mathrm{Q}_{i C}(i=1,2, \ldots, 12)$ are used to quantize the luminance and chrominance components, respectively.

$$
\begin{aligned}
& \mathrm{Q}_{12 \mathrm{~L}}=\left(\begin{array}{lll}
1 & 1 & 1 \\
& 1 & 1 \\
& 1 & 1 \\
1 & 2 & \\
& 1 & 1 \\
& 1 & 1 \\
1 & 2 & 1
\end{array}\right) \quad \mathrm{Q}_{12 \mathrm{C}}=\left(\begin{array}{lll}
1 & 1 & 1 \\
& 2 & 3 \\
& 3 & 3 \\
1 & 3 & 1 \\
& 2 & 3 \\
& 3 & 3 \\
1 & 3 & 2 \\
1 & 1 & -
\end{array}\right) \\
& Q_{12 L}=\left(\begin{array}{llllllll}
1 & 1 & 1 & 1 & 1 & 1 & 1 & 2 \\
1 & 1 & 1 & 1 & 1 & 1 & 1 & 2 \\
1 & 1 & 1 & 1 & 1 & 1 & 2 & 2 \\
1 & 1 & 1 & 1 & 1 & 2 & 2 & 3 \\
1 & 1 & 1 & 1 & 2 & 2 & 3 & 3 \\
1 & 1 & 1 & 2 & 2 & 3 & 3 & 3 \\
1 & 1 & 2 & 2 & 3 & 3 & 3 & 3 \\
2 & 2 & 2 & 3 & 3 & 3 & 3 & 3
\end{array}\right) \quad Q_{12 C}=\left(\begin{array}{llllllll}
1 & 1 & 1 & 2 & 3 & 3 & 3 & 3 \\
1 & 1 & 1 & 2 & 3 & 3 & 3 & 3 \\
1 & 1 & 2 & 3 & 3 & 3 & 3 & 3 \\
2 & 2 & 3 & 3 & 3 & 3 & 3 & 3 \\
3 & 3 & 3 & 3 & 3 & 3 & 3 & 3 \\
3 & 3 & 3 & 3 & 3 & 3 & 3 & 3 \\
3 & 3 & 3 & 3 & 3 & 3 & 3 & 3 \\
3 & 3 & 3 & 3 & 3 & 3 & 3 & 3
\end{array}\right) \\
& \mathrm{Q}_{9 \mathrm{~L}}=\left(\begin{array}{llllllll}
4 & 3 & 4 & 7 & 9 & 11 & 14 & 17 \\
3 & 3 & 4 & 7 & 9 & 12 & 12 & 12 \\
4 & 4 & 5 & 9 & 12 & 12 & 12 & 12 \\
7 & 7 & 9 & 12 & 12 & 12 & 12 & 12 \\
9 & 9 & 12 & 12 & 12 & 12 & 12 & 12 \\
11 & 12 & 12 & 12 & 12 & 12 & 12 & 12 \\
14 & 12 & 12 & 12 & 12 & 12 & 12 & 12 \\
17 & 12 & 12 & 12 & 12 & 12 & 12 & 12
\end{array}\right) \quad Q_{9 C}=\left(\begin{array}{llllllll}
4 & 6 & 12 & 22 & 20 & 20 & 17 & 17 \\
6 & 8 & 12 & 14 & 14 & 12 & 12 & 12 \\
12 & 12 & 14 & 14 & 12 & 12 & 12 & 12 \\
22 & 14 & 14 & 12 & 12 & 12 & 12 & 12 \\
20 & 14 & 12 & 12 & 12 & 12 & 12 & 12 \\
20 & 12 & 12 & 12 & 12 & 12 & 12 & 12 \\
17 & 12 & 12 & 12 & 12 & 12 & 12 & 12 \\
17 & 12 & 12 & 12 & 12 & 12 & 12 & 12
\end{array}\right)
\end{aligned}
$$

Our approach, in obtaining a value of scalar quantization, is to calculate the average value of matrix $\mathrm{Q}_{i}$ by using Equations 9 and 10. Example for matrix $\mathrm{Q}_{12}$, we obtaine two values of $Q_{L}=1.7031$ and $\mathrm{Q}_{\mathrm{C}}=2.6719$, while for matrix $\mathrm{Q}_{9}$ we get $\mathrm{Q}_{\mathrm{L}}=10.4375$ and $\mathrm{Q}_{\mathrm{C}}=12.9688$. Furthermore for each $\mathrm{Q}_{i}$ used in Photoshop is calculated the values of $Q_{L}$ and $Q_{C}$, and then embeded them to the Equations 7 and 8 to obtain the final formula of the $\mathrm{QYCbCr}$ color conversion and its inverse.

$$
\begin{aligned}
& Q_{L}=\frac{1}{N^{2}} \sum_{j=1}^{N} \sum_{k=1}^{N} Q_{i L}(j, k) \\
& Q_{C}=\frac{1}{N^{2}} \sum_{j=1}^{N} \sum_{k=1}^{N} Q_{i C}(j, k)
\end{aligned}
$$

Our proposed method can replace standard JPEG compression scheme (in the Figure 1) with a new one as shown in the Figure 4. This scheme is simpler and faster because it has integrated the quantization process into the RGB to QYCbCr color space conversion process and also the dequantization process into the $\mathrm{QYCbCr}$ to RGB color space conversion process. 


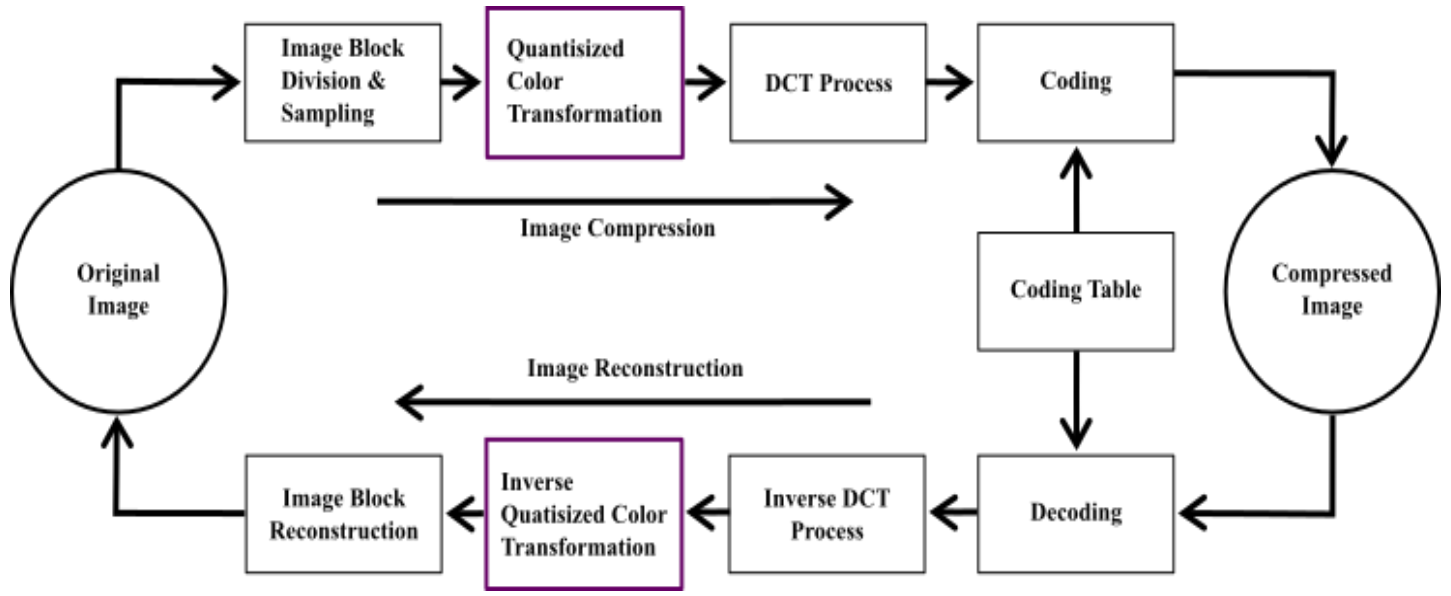

Figure 4. Our proposed method for new JPEG compression and decompression scheme

\section{EXPERIMENT RESULTS}

Our image compression and decompression algorithms have been implemented and tested in the Matlab programming language. The computer specifications used during the experiment has processor Dual Core i5, $1.8 \mathrm{GHz}, 4 \mathrm{~GB}$ DDR3L RAM memory and $128 \mathrm{~GB}$ SSD. The performance of the developed method is evaluated by measuring its computational time, compression ratio and image quality and then we compare them with those obtained by standard JPEG. Table 1 shows the performance of standard JPEG algorithm and our algorithm in term of computational time.

The first column shows 10 test images with different size and containing different characteristics of color, shape and texture. The second and third columns show the computational time of the standard JPEG compression algorithm and the proposed compression algorithm, respectively. From this table, it can be seen that computational time using QYCbCr reaches 4 to 8 times faster than standard JPEG. Here, we can note that the computational time of image compression depends not only on its size but also on the diversity of its color, shape and texture. The more varied colors, shapes and / or textures contained in the image, the longer of the computation time is required.

Table 1. Computational Time of JPEG Standard and JPEG using QYCbCr

\begin{tabular}{lcc}
\hline \multicolumn{1}{c}{$\begin{array}{c}\text { Image size } \\
\text { (Mega Pixel) }\end{array}$} & $\begin{array}{c}\text { JPEG standard } \\
\text { (second) }\end{array}$ & $\begin{array}{c}\text { JPEG using } \\
\text { QYCbCr (second) }\end{array}$ \\
\hline $512 \times 512=0.242$ & 4.411367 & 1.080972 \\
$1000 \times 483=0.483$ & 4.803166 & 1.324323 \\
$700 \times 800=0.560$ & 6.735555 & 1.332675 \\
$1630 \times 1480=2.412$ & 8.684127 & 1.347561 \\
$2102 \times 1587=3.336$ & 7.720825 & 1.530887 \\
$2192 \times 2020=4.428$ & 8.830231 & 1.061667 \\
$4482 \times 1210=5.423$ & 7.468400 & 1.711763 \\
$3758 \times 1907=7.167$ & 6.298628 & 1.927591 \\
$6500 \times 3637=23.641$ & 7.604468 & 1.110361 \\
$6446 \times 4096=26.403$ & 14.439853 & 1.611074 \\
\hline
\end{tabular}

Besides of computational time, we also measure the compression ratio and image quality resulting by the standard JPEG and our method. For this measurement, seven of quantization matrices from Photoshop CS: Q12, Q11, Q10, Q9, Q8, Q7, and Q6 are used, and just two of ten test images are presented. The first one is Lena image, has many areas with homogeneous colors, a little texture, but it has many shape variations. The second one is Baboon image has a heterogeneous color, shape and texture. The Compression ratio is calculated using equation (11) and the image quality is performed by measuring the peak signal to noise ratio (PSNR) as shown by equation (12). $f$ is uncompressed image, $f^{i}$ is compressed image, $f_{i j}$ and $f^{i}{ }_{i j}$ are pixel value of uncompressed and compressed image at position $(i, j)$.

Compression Ratio $=\frac{\text { Uncompressed Image Data }(\text { bytes })}{\text { Compressed Image Data }(\text { bytes })}$ 


$$
P S N R=20 \cdot \log \left(\frac{255}{M S E}\right) \quad \text { with } M S E=\sqrt{\frac{1}{M x N} \sum_{i=1}^{N} \sum_{j=1}^{M}\left(f_{i j}-f_{i j}^{i}\right)^{2}}
$$

Tables 2 and 3 show the calculation results of compression ratio and image quality (PSNR) for two examples Lena and Baboon images respectively. Figure 5 shows the graph of PSNR (dB) against the compression ratio of Table 2, while Figure 6 is the graph for Table 3. The curve in blue line represents the performance of JPEG with QYCbCr algorithm and the red line curve corresponds to the performance of standard JPEG. On these two graphs, it appears that both the ratio and quality of JPEG compression using QYCbCr are also better than standard JPEG. Images with heterogeneous content have characteristics increased in ratio and quality of compression. That's matter are not too significant, but an increase in ratio and quality of compression become more significant for a more homogeneous image.

Table 2. The Compression Ratio and Image Quality of Lena

\begin{tabular}{|c|c|c|c|c|}
\hline \multirow{2}{*}{$\begin{array}{l}\text { Photoshop } \\
\text { CS Q-Matrix }\end{array}$} & \multicolumn{2}{|c|}{ JEPG standard } & \multicolumn{2}{|c|}{$\begin{array}{c}\text { JEPG with proposed } \\
\text { QYCbCr }\end{array}$} \\
\hline & $\begin{array}{c}\text { PSNR } \\
(\mathrm{dB})\end{array}$ & $\begin{array}{c}\text { Compression } \\
\text { Ratio } \\
\end{array}$ & $\begin{array}{l}\text { PSNR } \\
(\mathrm{dB})\end{array}$ & $\begin{array}{c}\text { Compression } \\
\text { Ratio } \\
\end{array}$ \\
\hline 12 & 46.1425 & 2.401 & 46.4944 & 2.5398 \\
\hline 11 & 39.1108 & 4.5117 & 38.97 & 5.075 \\
\hline 10 & 36.9341 & 7.4566 & 36.3781 & 9.0022 \\
\hline 9 & 36.1172 & 9.4895 & 35.7291 & 11.0165 \\
\hline 8 & 35.3956 & 11.1696 & 35.2282 & 12.985 \\
\hline 7 & 35.3653 & 11.5038 & 35.146 & 13.1047 \\
\hline 6 & 34.5445 & 13.027 & 34.7052 & 15.2815 \\
\hline
\end{tabular}

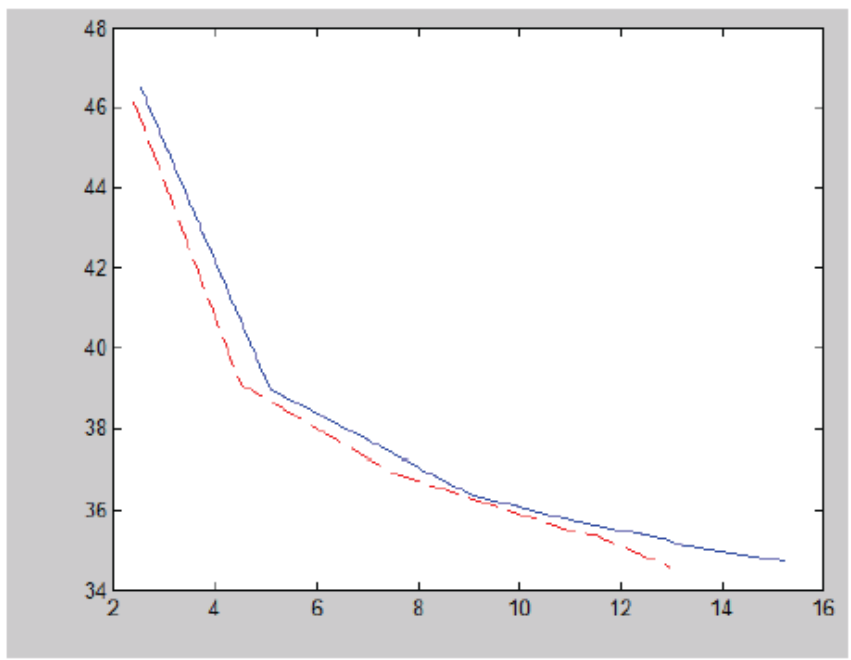

Figure 5. Curves of PSNR vs. Compression Ratio of Lena's Image

Table 3. The Compression Ratio and Image Quality of Baboon's Image

\begin{tabular}{ccccc}
\hline $\begin{array}{c}\text { Photoshop CS } \\
\text { Q-Matrix }\end{array}$ & $\begin{array}{c}c \\
\text { PSNR } \\
(\mathrm{dB})\end{array}$ & $\begin{array}{c}\text { Compression } \\
\text { Ratio }\end{array}$ & $\begin{array}{c}\text { JEPG using QYCbCr } \\
\text { PSNR } \\
(\mathrm{dB})\end{array}$ & $\begin{array}{c}\text { Compression } \\
\text { Ratio }\end{array}$ \\
\hline 12 & 46.1021 & 1.5344 & 46.4812 & 1.6066 \\
11 & 37.6955 & 2.3282 & 38.0211 & 2.5357 \\
10 & 33.8144 & 3.1437 & 34.0166 & 3.4111 \\
9 & 32.8049 & 3.5543 & 32.9975 & 3.7544 \\
8 & 32.0501 & 3.8570 & 32.2617 & 4.0147 \\
7 & 31.9122 & 3.8720 & 32.2215 & 4.059 \\
6 & 30.9142 & 4.1529 & 31.4006 & 4.4114 \\
\hline
\end{tabular}




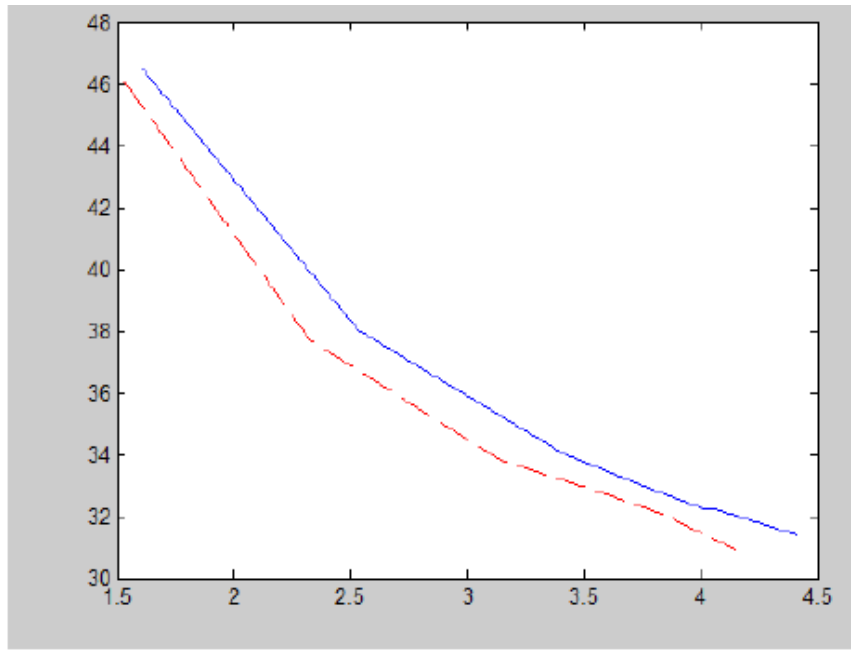

Figure 6. Curves of PSNR vs. Compression Ratio of Baboon's Image

\section{CONCLUSION}

One of the problem of the JPEG algorithm lies in the scheme (architecture) design of its development in order to get optimum of computation time, ratio and quality of the compression images. In this our study, the QYCbCr algorithm is proposed as one of development of Standard JPEG in which it merges two processes i.e., $\mathrm{YCbCr}$ and quantization in JPEG Standard forming one integrated process of color conversion derived from the chrominance and luminance quantization matrices. Experimental results that performed on the processor Dual Core i5, $1.8 \mathrm{GHz}, 4$ GB DDR3L RAM memory and 128 GB SSD using 10 test images with different size which are respectively containing different characteristics of color, shape and texture, show that the QYbCr algorithm has computational time 4 up to 8 times faster than standard JPEG algorithm. In addition, this method also provides better compression ratio and image quality. The future work, to obtain more efficient running time, the study can be develop by investigating the low level architecture of how $\mathrm{QYCbCr}$ algorithms are computed through hardware design.

\section{REFERENCES}

[1] Gregory K. Wallace, "The JPEG still picture compression standard", IEEE Transactions on Consumer Electronics, Vol. 38, No. 1, FEBRUARY 1992.

[2] Ahmed, N., Natarajam T., Rao K, "Discrete Cosine Transform“, IEEE, 1974.

[3] Syed Ali Khayam, "The Discrete Cosine Transform (DCT): Theory and Application", Michigan State University, March 10th 2003.

[4] Sari, Wellia Shinta, Rachmawanto, Eko Hari, Setiadi, De Rosal Ignatius Moses, Sari, Christy Atika, "A Good Performance OTP Encryption Image based on DCT-DWT Steganography”, TELKOMNIKA, Vol.15, No.4, December 2017, pp. 1987 1995 ISSN: 1693-6930, accredited A by DIKTI, Decree No: 58/DIKTI/Kep/2013 DOI: 10.12928/TELKOMNIKA.v15i4.5883

[5] Madenda Sarifuddin, "Pengolahan Citra dan Video Digital”, Book, 2016.

[6] Setyaningsih, Emy, Harjoko, Agus, "Survey of Hybrid Image Compression Techniques", International Journal of Electrical and Computer Engineering (IJECE) Vol. 7, No. 4, August 2017, pp. 2206 2214 ISSN: 2088-8708, DOI: 10.11591/ijece.v7i4.pp2206-2214

[7] Elawady, Iman, Lakhdar, Abdelmounaim Moulay, Mustapha, Khelifi, "The Noise Reduction over Wireless Channel Using Vector Quantization Compression and Filtering”, International Journal of Electricaland Computer Engineering (IJECE) ,Vol. 6, No. 1, February 2016, pp. 130 138 ISSN: 2088-8708, DOI: 10.11591/ijece.v6i1.8483

[8] Alen Docef, Faouzi Kossentini, Khanh Nguuyen-Phiand Ismaeil Ragab, "The Quantized DCT and Its Application to DCT-Based Video Coding”, IEEE Transaction on Image Processing, Vol. 11, No. 3, March, 2002.

[9] Sukirman Edi, "Peningkatan Kinerja Algoritma Kompresi dan Dekompresi JPEG Melalui Penggabungan proses DCT dan Kuantisasi”, Disertasi, October 2009.

[10] Sukirman Edi, Ernastuti, Madenda, Sarifuddin, "Model DCT-terkuantisasi dan IDCT-terkuantisasi untuk kompresi citra", Proceedings Seminar Ilmiah Nasional KOMMIT, 2010.

[11] Linlin Deng and Ping Fu, Aijun Sang and Silin Mang, "Quantization Algorithm for Color Image Coding Based on Multi-dimensional Vector Matrix DCT Orthogonal Transformation”, IEEE, 2009

[12] Mahendra M.Dixit, Priyatamkumar, "Comparative Analysis of Variable Quantization DCT and Variable Rank Matrix SVD Algorithms for Image Compression Application”, IEEE, 2010 
[13] Ramin Samadani, "Characterizing and Estimating Block DCT Image Compression Quantization Parameters", Asilomar Conference on Signals, Systems, and Computers, 30 October - 2 November 2005, Pacific Grove, CA, USA.

[14] Zimbico, A. Schneider, F., Maia, J, "Comparative study of the performance of the JPEG algorithm using optimized quantization matrices for ultrasound image compression", IEEE, 2014.

\section{BIOGRAPHIES OF AUTHORS}

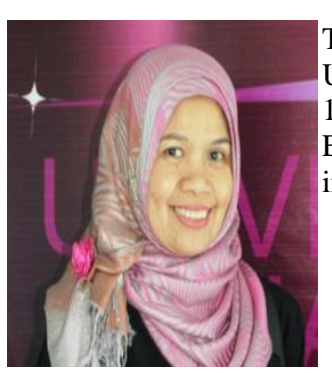

Trini Saptariani, SKom, MMSI - has received B.S. degree in Computer Science of Gunadarma University in 1988 and the Magister in Magister Management from Gunadarma University in 1994. She is currently an senior lecturer in the faculty of computer science and Information Engineering, Gunadarma University. Her current research interests include information system, image processing. Email: trini@ staff.gunadarma.ac.id

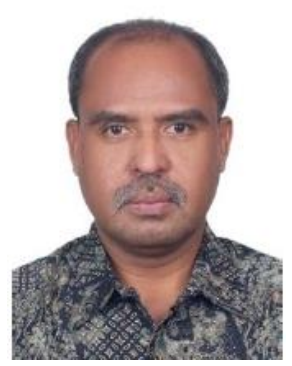

Prof. Sarifuddin Madenda - Currently Director of Doctoral Program of Information Technology and Computer Science, Gunadarma University - Indonesia. He received the B.S. degree from University of Indonesia, in 1989, the M.S. degree from Institute National des Sciences Appliquées de Lyon (INSA de Lyon) - French, in 1992, and the Ph.D. degree from University of Burgundy - French, in 1995. From 1995 to 1996, he was a Research Associate at LIESIB Laboratory - University of Burgundy. In 1997, he became a Lecturer in Computer Science Department, Gunadarma University - Indonesia. From 2002 to 2007, he was a researcher at Academic Research Consortium on digital imaging, video, audio and multimedia (CoRIMedia), Canada. His research interests are image processing: image compression, color imaging, image database and searching, medical image analysis, implementing of image processing algorithms on FPGA for real time image analysis. Email: sarif@ staff.gunadarma.ac.id

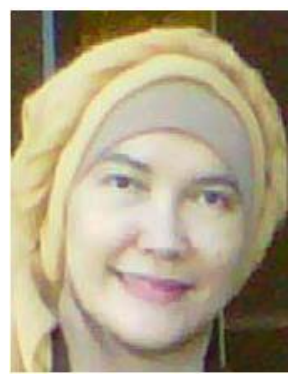

Dr. Ernastuti - has received B.S. degree in Mathematics from University of Indonesia in December 1985, and the M.S. in Computer Science from University of Indonesia, in July 1994, and $\mathrm{PhD}$ degrees in Computer Science from Gunadarma University, Indonesia, in April 2008. She is currently an associate professor in the faculty of computer science and Information Engineering, Gunadarma University. Her current research interests include graph theory and combinatorial optimization, graph-theoretic interconnection networks, parallel and distribute computing, and design and analysis of algorithms. Email: ernas_tuti@yahoo.co.id

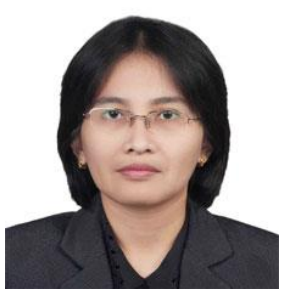

Dr. Widya Silfianti - now is a senior lecturer in the faculty of computer science and information engineering, Gunadarma Unviersity. She has received Computer Degree from Gunadarma University in April 1995, and the Magister from Gunadarma University in 1998, and $\mathrm{PhD}$ degrees in Computer Science from Gunadarma University, Indonesia, in 2010. Her current research interests include information system, database.Email: wsilfi@staff.gunadarma.ac.id. 